\title{
EPIDEMIA E PODER NO RECIFE IMPERIAL
}

\author{
Rosilene Gomes Farias*
}

RESUMO: Em 1856, durante a epidemia de cólera que atingiu o Recife, foram implantadas medidas de prevenção à doença, que pressupunham o controle social das camadas mais pobres da população. $\mathrm{O}$ artigo discute como essas medidas demonstram as relações de poder que envolveram autoridades públicas e médicos, no Recife do século XIX.

PALAVRAS-CHAVE: Relações de poder; saúde pública; Recife imperial.

\section{Epidemic and power in imperial Recife}

SUMMARY: In 1856, during the cholera epidemic that hit the reef, measures were implemented to prevent the disease, which presupposed the social control of the poorest sections of the population. The article discusses how these measures demonstrate the power relations involving public and medical authorities in Recife of the nineteenth century.

KEYWORDS: power relations; public health; Recife imperial.

\section{Epidemia y potencia en Recife imperial}

RESUMEN: En 1856, durante la epidemia de cólera que afectó a los arrecifes, se implementaron medidas para prevenir la enfermedad, lo que suponía el control social de los sectores más pobres de la población . El artículo describe cómo estas medidas demuestran las relaciones de poder que implican las autoridades públicas y médicos en Recife del siglo XIX.

PALABRAS CLAVE: relaciones de poder; salud públic; Recife imperiales.

*Pós-doutoranda do Programa de Pós-Graduação do Departamento de História da Universidade Federal de Pernambuco. Email: rosegfarias@ hotmail.com. 


\title{
A medicina busca legitimação
}

\begin{abstract}
Acerca da sociedade, de sua saúde e suas doenças, de sua condição de vida, de sua habitação e de seus hábitos, começara a se formar um saber médico-administrativo que serviu de núcleo originário à economia social e à sociologia do século XIX. E constituiu-se, igualmente, uma ascendência político-médica sobre uma população que se enquadra com uma série de prescrições que dizem respeito não só à doença, mas às formas gerais da existência e do comportamento (Foucault, 1979, p.202).
\end{abstract}

Durante o período colonial, o modelo de organização dos serviços de saúde adotado no Brasil era semelhante àqueles que vigoravam em Portugal. A estrutura administrativa da Fisicatura era representada pelo Físico-Mor e pelo Cirurgião-Mor do Reino, que tinham prerrogativas de estabelecer regimentos sanitários e expedir comunicados, alvarás e provisões para os representantes no Brasil. Em 1782, D. Maria I criou a Junta do Proto-Medicato, órgão substitutivo da Fisicatura. Constituído por um Conselho de sete deputados, a Junta tinha poderes para fiscalizar o exercício da medicina e controlar a comercialização de medicamentos. Os serviços de saúde permaneceram sob a responsabilidade das Santas Casas de Misericórdia, dos hospitais militares e das enfermarias das ordens religiosas, e eram prestados de forma bastante precária. Nesses locais, havia carência de médicos e as instalações físicas eram inadequadas.

Com a chegada da Família Real ao Brasil, em 1808, D. João restabeleceu os cargos de Físico-Mor e Cirurgião-Mor. No mesmo ano, com o objetivo de suprir a escassez de médicos, ele criou a Escola de Cirurgia e o Hospital Real Militar, ambos em Salvador. Com a transferência da Corte para o Rio de Janeiro, D. João VI, autorizou a instalação da Escola de Anatomia, Cirurgia e Medicina, e do Hospital Militar do Rio de Janeiro. Em 1828, os cargos de Físico-Mor e Cirurgião-Mor do Império foram extintos e a responsabilidade pelos serviços de saúde pública passou às Câmaras Municipais, o que causou desconforto entre os médicos. No ano seguinte, buscando restaurar o poder perdido para as Câmaras, um grupo de médicos fundou a Sociedade de Medicina do Rio de Janeiro que, em 1835, passou a se chamar Academia Imperial de Medicina, um órgão de consultoria para as autoridades do governo nas questões relacionadas à higiene pública nas cidades. ${ }^{1}$ Durante todo o Império esses médicos buscaram uma maior influência junto às autoridades brasileiras, numa tentativa de estruturar e fortalecer a medicina para torná-la única forma de cura legítima no Brasil. Com esse intuito, realizaram melhorias no ensino da medicina e iniciaram o combate mais ostensivo aos diversos concorrentes (Sampaio, 2001, p.24). 
Em 1841, alguns médicos pernambucanos formados na Europa, sobretudo na França, fundaram a Sociedade de Medicina de Pernambuco, com o intuito de valorizar a ciência médica e participar da regulamentação das práticas de higiene pública junto ao governo provincial. $^{2}$ Essa seria a primeira iniciativa de médicos e farmacêuticos para atuar como uma força conjunta e organizada. Dessa sociedade saíram os médicos que se achariam à frente dos debates em torno da salubridade do Recife de então. Reunidos, esses higienistas procuraram estabelecer a "constituição médica" da cidade, ou seja, realizaram um estudo para conhecer os problemas de salubridade relacionados às enfermidades que grassavam no lugar (Arrais, 2004, p.364).

Um aumento do prestígio dos médicos ocorreu com a criação do Conselho de Salubridade Pública, em 1845. Tendo como presidente o médico Joaquim Aquino da Fonseca, o órgão teve a incumbência de melhorar as condições sanitárias e auxiliar no combate às epidemias que assolavam o Recife. Através do órgão, os médicos ganharam lugar nas esferas decisórias do Estado, estabelecendo uma forte ligação com as autoridades locais, e podiam propor políticas de higienização da cidade, que prescindiam da aprovação do governo para serem executadas. O combate à prostituição, à convivência dos escravos nos espaços públicos, ao despejo de dejetos nos rios e no mar, e o ordenamento das ruas foram algumas das preocupações nas campanhas de higienização realizadas pelo órgão. ${ }^{3}$

Os antigos hábitos de sepultamento também foram alvos da preocupação do Conselho de Salubridade, que procurava combater as os enterros no interior das igrejas. Pereira da Costa descreve como os templos eram tomados pelo odor exalado por esses sepultamentos: "A casa de Oração se tornara, assim, uma morada de horror onde, em vez de aspirarem-se fragrâncias de aroma e puro incenso, aspiram-se mefíticas exalações” (Costa, 1984, p.178). Contudo, a população insistia em praticá-los, burlando as recomendações dos médicos. A criação de um cemitério fora da cidade também não teve uma recepção amistosa por muitos habitantes do Recife, sobretudo aqueles que se ressentiam por ver suas crenças religiosas sendo ofendidas. ${ }^{4}$ Por outro lado, parece legítimo pensar que as mudanças nos rituais fúnebres tenham contrariado os interesses dos que lucravam com o comércio vinculado a esse setor. Sobre a reação de alguns recifenses, após a inauguração do cemitério, Mário Sette relata: “Em 1850 veio o Cemitério Público de Santo Amaro. Não se fariam mais enterros em igrejas. Repulsas, queixas, escrúpulos, incidentes, até cadáveres retirados clandestinamente das catacumbas. Foi preciso agir pela força. A guarda cívica interveio" (Sette, 1948, p.48). 
O disciplinamento da pobreza foi outro alvo da intervenção do Conselho. Para as autoridades, a presença de pobres, geralmente doentes, em pontos movimentados da cidade, representava um risco à saúde pública e colocava a cidade em descrédito aos olhos dos estrangeiros. Por isso, médicos e políticos insistiam na necessidade de se retirar das ruas esses indivíduos, alegando que poderiam constituir focos de contaminação. A medicina estendia, assim, o seu olhar e passava a intervir na sociedade como um todo e não apenas no corpo do doente, através de medidas preventivas e do combate às doenças urbanas (Miranda, 2001, p.106).

A aproximação entre médicos e autoridades aponta para uma "harmonia de interesses" que pode ser compreendida ao se considerar os ideais de modernização e civilização que os governantes ambicionavam introduzir no cotidiano do Recife oitocentista. Os referidos ideais ganhavam legitimidade através do discurso dos higienistas, que encontravam nas autoridades o respaldo necessário tanto para executar os projetos de higienização da cidade quanto para combater os seus concorrentes.

No relatório sobre a epidemia do cólera que atingiu o Recife em 1856, enviado pelos médicos ao Presidente da Província, é possível observar a importância desse elo entre as duas partes, sobretudo nas decisões acerca do combate à doença:

\begin{abstract}
Em todas as questões de higiene social descobre-se um lado puramente médico e outro puramente civil. Aquele está circunscrito nas leis e nos pormenores físicos e orgânicos e este no direito público ou na força das massas. A higiene pública tem, portanto, uma administração fundada nos conhecimentos médicos e na força e recursos do Estado. Observando-se as alterações ou os seus agentes minorativos ou mesmo destrutivos, se exerce uma administração médica e, empregando-se os recursos do estado na intenção de garantir a saúde pública, se exerce a administração civil. ${ }^{5}$
\end{abstract}

Estudando as políticas de saúde no século XVIII, Foucault oferece pistas sobre o que parecia ser o caminho almejado por esses médicos que se colocavam ao lado dos governantes na luta contra os males que assolavam o Império:

\footnotetext{
O médico se torna o grande conselheiro e o grande perito, se não na arte de governar, pelo menos na de observar, corrigir, melhorar o corpo social e mantê-lo em um permanente estado de saúde. E é sua função de higienista, mais que seus prestígios de terapeuta, que lhe assegura esta posição politicamente privilegiada (Foucault, 1979, p.203).
}

A influência que exerciam na administração da cidade cresceu gradativamente ao longo dos cinco anos de existência do Conselho de Salubridade Pública. Seus membros 
procuraram intervir diretamente na desordem urbana e combater a prática ilegal da medicina. Sobre esse acréscimo de poder que os doutores experimentam nesse momento, Joel Outtes argumenta:

\begin{abstract}
Quando passa a haver por parte do Estado um interesse em organizar a população através da produção de suas condições de vida, o saber sobre a doença elaborado pela medicina aparece como se feito sob medida, adequando-se perfeitamente. $\mathrm{O}$ discurso da saúde implica considerações totalizantes sobre a sociedade. A implantação do projeto da medicina social passa pela ascensão dos médicos à posições no aparelho de Estado e nas entidades da sociedade civil, assim como o exercício do poder do Estado, a partir do prisma da saúde, passa pela cooptação dos médicos à sua estrutura (Outtes, 1997, p.25).
\end{abstract}

Em 1853, foi criada a Comissão de Higiene Pública, também presidida por Aquino Fonseca. Com atribuições mais amplas que as do Conselho, a Comissão tinha autonomia para regulamentar as leis e punir os infratores em assuntos de higiene. A criação desse órgão ampliou os poderes dos médicos, que acentuaram ainda mais a perseguição aos concorrentes que atuavam na província (Andrade, 1989, p.52).

As transformações políticas e econômicas ocorridas no Brasil oitocentista afetaram diretamente as relações entre os governantes e os médicos. Seus saberes foram introduzidos no cotidiano da sociedade, auxiliando no processo de legitimação do poder do Estado. Para tanto, foi preciso organizar a formação de profissionais habilitados no país e criar uma legislação que reprimisse a atuação de curadores, rezadores, feiticeiros e homeopatas. Mas o controle da profissão médica e o combate às práticas ilegais de cura não ocorriam de modo eficiente e, pesar de algumas denúncias e prisões, de forma geral, não havia punição. Isso acontecia porque a legislação que regulava o exercício da medicina não tinha respaldo social para ser cumprida, visto que antigas práticas de cura ainda se achavam bastantes arraigadas no cotidiano da população (Diniz, 1997, p.370).

Apesar da tentativa dos médicos de salvaguardar a exclusividade no seu espaço de atuação, curandeiros, benzedeiras, barbeiros sangradores e outros agentes de cura continuaram convivendo no Brasil com a medicina procedente da Europa durante todo o século XIX. Nem mesmo a proibição legal impedia que fossem procurados pelos mais diferentes setores da população ao longo de todo o Império. Buscando explicações para essa popularidade dos curandeiros, desde os tempos da colônia, Tânia Pimenta argumentou:

O modo como boa parte da população via os curandeiros, cujos serviços não eram solicitados apenas por falta de médicos ou cirurgiões, ou porque não podiam pagálos, como pretendiam esses últimos. Os curandeiros eram requisitados, muitas vezes, por serem mais eficientes, fosse para tratar moléstias leves, fosse para cuidar das sérias (Pimenta, 2003, p.323). 
Para a autora, a frequência dos anúncios dos curandeiros oferecendo os seus serviços nos jornais da Corte sinaliza para o fato de que o conceito da população a respeito dos curadores tenha se mantido ao longo de várias décadas.

Ensina Gabriela Sampaio que esses agentes de cura eram tratados pelos higienistas e pelo governo com adjetivo "charlatões". Eles compunham uma diversidade enorme de criminosos: havia curandeiros, homeopatas, boticários, parteiras, médicos não habilitados pelas escolas de medicina, práticos, leigos fabricantes de remédios, etc. Apesar de não terem enfrentado anos de estudos e não possuírem noções básicas de ciência, eles desfrutavam de uma influência junto à população que os médicos levaram anos para obter. Por isso, cobravam das autoridades providências a fim de conseguirem estabelecer a sua prática como hegemônica. Foi necessário criar a abrangente categoria "charlatão", que dizia respeito a todo aquele que praticasse uma medicina diferente da científica. O termo denominava uma figura hostil em oposição à identidade do médico, portador dos saberes da ciência e os únicos profissionais que deveriam figurar como confiáveis para questões de saúde (Sampaio, 2001, p.28-53).

Não eram poucos os médicos que protestavam contra a ineficácia das leis que, por serem pouco rigorosas, acabavam permitindo o livre exercício das artes de curar.

Para além da legislação e da burocracia, o próprio esforço por parte dos médicos em tentar estabelecer o monopólio de suas atividades indica-nos que os terapeutas populares continuaram a exercer seu ofício, como o fazem hoje em dia, e a população continuou a recorrer a esses últimos e a reconhecer e sua competência para tratar de diversos males (Pimenta, 2003, p.326).

A Câmara Municipal era responsável pela fiscalização do cumprimento das leis e reclamava da ausência de recursos para realizar suas inúmeras atribuições. Faziam parte das suas funções a construção de cemitérios, a limpeza das ruas e a conservação dos calçamentos; que deveriam ser executadas utilizando fundos da Tesouraria Provincial. Pressionada pelo Conselho de Salubridade, a Câmara elaborava posturas que não tinha condições de por em prática, seja pela falta de verbas ou mesmo por não haver um número razoável de funcionários que fiscalizasse o cumprimento das leis. Os poucos fiscais, quando conseguiam multar alguém por descumprir alguma postura, não conseguiam provar o delito por falta de pessoas que se dispusessem a testemunhar sobre o ocorrido. Assim, os vereadores eram acusados, sobretudo pelos higienistas, de inércia e respondiam dizendo que os médicos ansiavam por ver as medidas executadas, sem considerar as dificuldades de se estabelecer e 
fazer cumprir regras que envolvem a vida de toda uma comunidade. Segundo Raimundo Arrais, "Nas críticas que a Câmara endereçava à precipitação dos higienistas, eles afirmavam que os médicos andavam com a cabeça em Paris, ignorando as condições reais e específicas que um administrador precisava que considerar" (Arrais, 2004, p.428-432).

É importante lembrar que as queixas dos médicos sobre a falta de fiscalização das práticas de cura eram um problema antigo. Nos tempos da Colônia, mesmo dispondo de um regimento que determinava punições para aqueles que medicassem ilegalmente, na prática a Fisicatura não dispunha de delegados e subdelegados do físico-mor e do cirurgião-mor em número suficiente, o que acabava dificultando a fiscalização em um território tão amplo (Pimenta, 2003, p.310).

As atividades de cura ilegais preocupavam os doutores, sobretudo por ameaçarem a sua subsistência, visto que eram procuradas por diversos setores da população, abrindo uma larga concorrência no campo de atuação na sociedade. Entretanto,

\begin{abstract}
Os médicos não pretendiam apenas ser mais uma opção de cura respeitável e merecedora da confiança das pessoas simplesmente em função de seu compromisso com a ciência. Seu objetivo era ser a única opção existente, para que conseguissem definitivamente conquistar o poder e prestígio que acreditavam merecer como representantes da doutrina científica. Para tanto, necessitavam do apoio do poder que legisla, pois só com suas armas não conseguiriam atingir a legitimidade desejada. Os interesses de ambos eram comuns: a saúde dos povos deveria ser uma meta perseguida tanto por médicos quanto por autoridades (Idem, p.54-55).
\end{abstract}

Durante todo o século XIX, as contendas envolvendo médicos e praticantes das mais diversas formas de curar (curandeiros, espíritas, boticários, homeopatas e médicos estrangeiros) faziam parte do repertório de notícias que cotidianamente frequentavam os jornais recifenses. Muitas vezes, a imprensa ofereceu um grande apoio aos médicos na luta contra o charlatanismo, publicando artigos que procuravam desqualificar a atuação dos concorrentes. Em um desses artigos, publicado no Diário de Pernambuco, alguns médicos cobravam da Câmara Municipal uma maior vigilância sobre as práticas de restabelecimento da saúde, sobretudo no sentido de proibir a atuação de curandeiros, pois eles não estariam aptos para exercer a medicina. Na mesma oportunidade, deixaram a sua impressão sobre os tratamentos ministrados aos pacientes com sintomas de cólera, através das práticas do curandeirismo. Para eles, os doentes "escapariam da moléstia, se não morressem da cura". 6

A atitude da imprensa nem sempre era parcial. Ao mesmo tempo em que se encontravam registros como o citado anteriormente nos jornais, também era comum a publicação de notícias sobre a cura de doentes que estiveram aos cuidados dos ditos 
“charlatões". Um bom exemplo disso ocorreu no Recife, onde as peripécias do pai Manoel, um curandeiro africano que alegava conhecer um remédio capaz de curar o cólera, e o seu "remédio milagroso" foram largamente noticiados pelos periódicos locais (Farias, 2012). Por outro lado, os doutores e a sua ciência também foram alvos de críticas da imprensa, sobretudo nos momentos de maior morticínio, quando todas as medidas pareciam inúteis, o que revelava que a medicina ainda não evoluíra o suficiente para obter exclusividade em seu campo de atuação.

\section{Cólera: Infecção ou contágio?}

O surgimento do cólera no Recife, em janeiro de 1856, ocorreu em meio a um debate médico sobre as teorias que tentavam explicar a disseminação da doença e que foi decisivo na elaboração das medidas de prevenção, das estratégias de socorro aos doentes e das tentativas de erradicação do mal.

No século XIX, as teorias sobre contágio e infecção dividiam a opinião dos médicos europeus e brasileiros, que tentavam explicar a forma de propagação das doenças epidêmicas. Sobre o cólera, não havia unanimidade entre os médicos para explicar as suas causas. Alguns acreditavam em contágio por meio de micro-organismos e outros defendiam a teoria dos miasmas. Essa teoria foi o alicerce para as explicações que surgiram sobre a doença e uma tendência predominante na medicina oitocentista. Fundava-se na crença da qualidade do ar como elemento determinante da saúde. Assim, quando ele apresentasse uma má qualidade, sobretudo quando estivesse contaminado com matéria orgânica em decomposição (substâncias animais e vegetais em estado de putrefação), seria considerado fonte de doenças para a população (Chernoviz, 1890, p.127).

A infecção miasmática seria resultante da adulteração do ar por vapores pútridos que formavam os miasmas. Estes, por sua vez, tornariam aqueles que os respirava vulneráveis às doenças epidêmicas, como o cólera. A crença na teoria dos miasmas explica a preocupação dos médicos com a qualidade e a circulação do ar. Para eles, o ar viciado das habitações superlotadas seria um poderoso agente disseminador de enfermidades. Ao explicar o surgimento das epidemias, os infeccionistas relacionavam clima e doença, enfatizando os riscos dos miasmas exalados pelos charcos e pântanos aquecidos, sobretudo nas regiões tropicais. Por isso, temiam sempre a entrada do verão, quando o calor intensificava a produção de vapores das matérias em decomposição acumuladas nessas áreas, fazendo surgir às enfermidades. Também suspeitavam que esses vapores infectavam o ar e incubavam as 
epidemias. Por isso, os aspectos físicos e as características de ocupação do Recife inquietavam os partidários dessa teoria. ${ }^{7}$

O Recife foi edificado em um terreno de aluvião, na embocadura dos rios Capibaribe e Beberibe, os quais, sofrendo continuamente a influência da mistura das águas com as do mar, resultavam na formação de grandes pântanos ou mangues em diversos pontos da cidade, porque os rios se subdividem e se emaranham por todos os recantos. Por outro lado, a situação do solo da cidade, quase ao nível do mar, faz com que o lençol de água subterrâneo se encontre muito na superfície da terra dando a impressão continuada de uma umidade doentia e incomodativa em muitos lugares. Foi sobre este solo de péssima constituição geológica que os primitivos habitantes da antiga Mauricía elevaram as suas primeiras casas, e sem o prévio dessecamento e drenagem do subsolo, sem impermeabilização ou preparo de espécie alguma (Galvão, 1921, p.192).

Os médicos recifenses defensores da teoria miasmática reconheciam os prejuízos que o meio ambiente corrompido e a proximidade dos pântanos poderiam causar à saúde da população. Contudo, mesmo entre esses médicos havia alguns que admitiam outras causas para as epidemias. Tal qual o Dr. Aquino, eles acreditavam que tanto o calor e a unidade do ar quanto os vapores exalados por materiais orgânicos em decomposição tornavam o ambiente propício ao surgimento de doenças epidêmicas ${ }^{8}$, mas consideravam também a possibilidade de que elas resultassem de outros fatores como a importação e o contágio. Segundo Chernoviz, contágio podia ser entendido como a propriedade que algumas doenças possuíam de se propagar através do contato direto com os doentes ou mesmo com objetos por eles manipulados (Chernoviz, 1890, p.182). Assim, as enfermidades surgiriam a partir de um veneno específico que, uma vez produzido, podia se propagar independente das condições ambientais, apenas pelo contato com pessoas ou objetos infectados com o "germe" da doença. Este pensamento era compartilhado pelos médicos Joaquim Aquino da Fonseca e Cosme de Sá Pereira, ambos os presidentes da Comissão de Higiene durante a epidemia no Recife. ${ }^{9}$

Minoritários e muito influentes no Recife, os contagionistas interpretavam o cólera como uma doença exótica, que só por meio da sua importação e transmissibilidade havia alcançado as terras brasileiras. Assim, insistiam na necessidade da adoção de medidas de isolamento, visando impedir o avanço da epidemia. O cordão sanitário e a quarentena, práticas sempre associadas, eram vistos com medidas essenciais porque evitavam a entrada e a saída de pessoas contaminadas na cidade. O cordão sanitário deveria utilizado como o meio de controle das pessoas e mercadorias, sendo vetada a entrada na província daqueles originários de lugares já invadidos pela epidemia. Essa era uma medida especialmente difícil de colocar em prática, na medida em que impunha sérias restrições ao comércio e ao 
abastecimento dos gêneros de primeira necessidade. Por sua vez, a quarentena consistia no isolamento, por tempo determinado e em local afastado da cidade, de pessoas vindas por terra ou por mar para que se observasse a presença ou não de doença contagiosa. Os dois procedimentos tinham por fim evitar o contágio. No caso da quarentena, deveria haver um lugar específico para sua aplicação: os lazaretos ou hospitais de isolamento (Diniz, 1997, p.420).

Os infeccionistas argumentavam que os cordões sanitários e as quarentenas eram medidas inúteis, visto que o cólera era produzido por causas locais. Entre eles, os poucos que admitiam a possibilidade de transmissão acreditavam que isso não ocorreria por meio de pessoas ou de objetos e sim pelo ar, com a doença deslocando-se de um lugar para outro através dos ventos. Isso tornava inútil qualquer medida de isolamento adotada para impedir a sua chegada. Para os adeptos da teoria infeccionista, era preciso higienizar a cidade para fazer com que ela deixasse de ser um local propício ao surgimento de epidemias (Andrade, 1989, p.28-29).

A incerteza quanto à natureza dos males epidêmicos continuava presente no início do século XX. O estudo realizado por Christiane Souza sobre o surto da gripe espanhola que atingiu a Bahia em 1918 demonstra que, mesmo não tendo vitimado tantas pessoas como em São Paulo ou no Rio de Janeiro, a doença revelou a fragilidade do sistema médico e das políticas de saúde pública locais. Nas primeiras semanas da epidemia, os médicos realizaram um debate sobre a origem e o nível de risco representado pela gripe para a população da região. A incerteza, que se apresentava nos debates, levou à hesitação em recomendar medidas de proteção. Tal qual ocorrera em Pernambuco, enquanto as vítimas da gripe começavam a morrer, a comissão médica nomeada pelo governo para recomendar medidas de enfrentamento para a epidemia perdia semanas investigando e debatendo sobre a origem e o caráter contagioso ou infeccioso da doença (Souza, 2009).

No Recife oitocentista, essa discussão envolvia, além dos médicos, muitos interesses políticos, sociais e econômicos. Se considerada contagiosa, a epidemia deveria ser combatida com medidas de controle e isolamento dos doentes, sendo as quarentenas imprescindíveis para isso. Contudo, essa estratégia de segregação causaria constrangimentos à população por dificultar a livre circulação daqueles que chegassem ou saíssem da cidade por terra ou por mar. Na medida em que interferiria no fluxo de embarque e desembarque das mercadorias no porto, a quarentena também traria danos à economia local, bem como das outras províncias e 
até outros países que mantivessem relações comerciais com Pernambuco e que, para tanto, utilizassem o porto.

Na Europa, durante o século XIX, a teoria do contágio passou por um período de desvalorização e pouca aceitação entre os médicos em função da sua imediata ligação com o tema da adoção das quarentenas. Elas representavam uma fonte de prejuízos econômicos e de controle burocrático para a classe ascendente de comerciantes e industriais, tornando-se suspeitas para os partidários da ideologia liberal. Com o auxílio de seus representantes políticos e de setores da imprensa, eles tentavam desqualificar as quarentenas, argumentando que elas não possuíam fundamento científico. Assim, as questões acerca do contágio envolveriam, além dos debates teóricos dos médicos, também interesses políticos e sociais. Nesse cenário, os médicos, na sua grande maioria adeptos do liberalismo, teriam assegurada a predominância da teoria infeccionista. Segundo Sidney Chalhoub, ficou evidente que "os debates entre médicos das duas correntes teóricas eram constitutivos do processo histórico mais amplo de transformações sociais e econômicas pelas quais passava o ocidente naquele período" (Chalhoub, 1996, p.170-171).

A resistência de boa parte dos médicos recifenses à ideia de contagiosidade do cólera abre espaço para que se pense essa atitude estabelecendo relações com os argumentos discutidos por Chalhoub. Sobretudo, em se tratando do Recife revelado no primeiro capítulo desse estudo: um Recife que era o porto brasileiro mais próximo da Europa, com uma forte vocação comercial e porta de entrada das ideologias liberais que vinham de lá por meio de jornais, revistas e panfletos, e que ganhavam aqui fervorosos admiradores. Parece razoável supor que a delonga para que se tomasse uma medida mais austera de combate à epidemia, o que certamente traria consequências para a economia local, foi influenciada também por comerciantes e industriais. Seus interesses podem ter figurado como pano de fundo para as discussões entre os médicos representantes das duas correntes teóricas.

Algo semelhante ocorreu em 1900, quando a peste bubônica surgiu pela primeira vez no Rio de Janeiro. Alguns meses antes de chegar à cidade, a doença já causava apreensão às autoridades de saúde. O episódio foi estudado por Dilene Nascimento e Matheus Silva, que analisaram um debate trazido a público pelo Jornal do Commercio, entre agosto e setembro de 1899. A questão envolvia duas autoridades sanitárias, Nuno de Andrade, diretor-geral de Saúde Pública, e Jorge Pinto, diretor de Higiene e Assistência Pública do Estado do Rio de Janeiro, e referia-se às medidas tomadas pelo governo federal para evitar a chegada da peste bubônica ao Brasil, a partir de uma epidemia existente na cidade do Porto, Portugal. Muitas 
das críticas do diretor de Higiene e Assistência Pública do Estado do Rio de Janeiro eram voltadas às medidas restritivas, que impediam o desembarque de alguns produtos e obrigavam os navios a ficarem parados no porto da então capital da República, motivando a elevação dos preços dos produtos importados e causando prejuízos econômicos. Para os autores, a posição liberal de Jorge Pinto a respeito da relação entre Estado e economia, fica evidenciada na medida em que, para ele, os interesses do comércio deviam prevalecer, cabendo ao governo não interferir nas relações comerciais (Nascimento, 2013, p.171).

\section{A epidemia, da espera ao enfrentamento}

As medidas preventivas que visavam impedir que a epidemia de cólera atingisse o Recife tiveram como pressuposto o caráter contagioso da doença. Havia também a suspeita de que o contágio se dava ao longo das rotas comerciais e que atingia, sobretudo, as camadas mais pobres da população. Por isso, os médicos acreditavam que o Recife figurava como uma vítima em potencial, visto que tinha um porto com grande movimentação de navios vindos de outras províncias e também do exterior. Também se preocupavam com grande número de habitantes pobres morando em mocambos construídos em lugares alagadiços. Em consonância com a posição dos higienistas, o presidente da província enviou ofício à Câmara Municipal recomendando a implantação medidas visando tornar a cidade menos insalubre.

(...) recomendo que hajam de expedir suas ordens a fim de ativar-se a limpeza das ruas desta cidade, cumprindo que sejam removidos, quanto antes, todos os monturos que forem encontrados e extintos quaisquer focos pestilenciais, e bem assim que sejam fiscalizados as tabernas e outros lugares de mercados para evitarse a venda de Gêneros alimentícios em estado de ruína. ${ }^{10}$

Para um maior controle do movimento portuário, a Provedoria de Saúde do Porto sugeriu ao governo provincial que os navios vindos de lugares infectados não tivessem comunicação imediata com a terra. Antes que isso ocorresse, eles seriam submetidos a uma quarentena de observação, devendo os passageiros seguir para o lazareto da ilha do Pina, onde seriam acomodados e teriam assistência médica. ${ }^{11}$ Também ficou estabelecido que deveria ser apresentada uma carta de saúde no ato da entrada do navio, com o objetivo de avaliar o estado do porto de onde ele procedia. ${ }^{12}$

A leitura da documentação que trata do funcionamento do porto do Recife demonstra que houve dificuldades na implantação das medidas de segurança, especialmente as quarentenas. As medidas preventivas não foram tão bem-vindas e, para colocá-las em prática, 
a Vigilância Sanitária do Porto requisitou a colaboração da força policial para evitar que pessoas que pudessem estar infectadas deixassem o lazareto e circulassem pelas ruas da cidade, antes do término do tempo previsto para o isolamento.

Tendo seguido para a Ilha do Pina os passageiros do vapor São Salvador e constando agora pelas comunicações que o cólera epidêmico reina no Pará em grande escala, uma força composta de número suficiente de praças e comandada por oficial será postada naquela Ilha do Pina afim de evitar que as pessoas de terra se comuniquem com os que se acham no Lazareto, ou algumas delas venham à cidade antes de finalizar o prazo marcado. ${ }^{13}$

A citação acima sugere, o lazareto do Pina permaneceu guardado por sentinelas que tinham a função de impedir a comunicação entre os indivíduos isolados na ilha e os moradores da cidade. Os contatos indispensáveis ocorriam durante o dia, exigindo-se que o visitante mantivesse dez braças de distância entre o mar e a terra. ${ }^{14}$ Essas medidas atenderam as duas vertentes do pensamento médico, já que infeccionistas e contagionistas tiveram suas reivindicações respeitadas. Mas, mesmo aqueles que não acreditavam na contagiosidade do cólera convenceram-se dela ao constatar que a epidemia, apesar das quarentenas e cordões sanitários, invadira a cidade. ${ }^{15}$

Após a falência das medidas preventivas para impedir a chegada da epidemia, o governo provincial decretou estado de peste e consultou a Comissão de Higiene Pública sobre as providências a serem tomadas. Ela decidiu que a cidade deveria ser dividida em distritos, que ficariam subordinados a uma comissão médica. A finalidade desta medida era descentralizar o tratamento dos doentes, o que evitaria o pânico e os riscos de infecção advinda do deslocamento e da concentração de muitos doentes em um espaço confinado. Para tanto, foram instalados cerca de quinze hospitais provisórios exclusivos para coléricos em toda a cidade do Recife. ${ }^{16}$

A preocupação com a possibilidade de contágio também levou à criação de uma companhia de desinfetadores, que deveria se deslocar para os locais onde aparecessem novos casos da doença, munidos de utensílios e agentes químicos necessários para realizar a desinfecção imediata. A companhia de desinfetadores era composta por um médico diretor e seus quatro auxiliares, um responsável pela preparação e distribuição das soluções desinfetantes, encarregados da desinfecção em cada freguesia, quatro serventes (dois caiadores e dois lavadores) e um ajudante para o depósito dos produtos químicos. Também foi criado um serviço de ambulâncias: carros para conduzir os doentes para os hospitais e os cadáveres para o cemitério. ${ }^{17}$ 
A Comissão alertou o governo da província para a necessidade de centralização das informações sobre a epidemia. Isso se daria mediante a elaboração de relatórios minuciosos pelas autoridades médicas envolvidas na campanha de combate ao cólera, que seriam direcionados à presidência da Província. Os médicos deveriam fazer um acompanhamento do avanço da epidemia, registrando as informações colhidas diariamente sobre o aparecimento de novos casos da doença, os tratamentos empregados, a mortalidade e o progresso e declínio da epidemia. Deveria haver um rígido controle dos doentes, com certidão do médico responsável pelo tratamento do enfermo e, em caso de morte, a causa deveria ser registrada. ${ }^{18}$

Um maior controle das autoridades médicas sobre a evolução da epidemia significou também certa "invasão" da vida privada da população visto que, em muitos casos, isso era realizado com visitas médicas domiciliares. Dessa forma, os doutores vistoriavam as casas e podiam identificar focos de insalubridade e novos casos da doença. Também havia o risco dos enfermos serem retirados compulsoriamente das suas residências, visto que a política para as vítimas da doença era de mantê-las nos lugares mais distantes da cidade (para isso foram criados hospitais exclusivos para coléricos). ${ }^{19}$ Assim, o medo de serem afastados das suas famílias pode ter figurado como motivo para que muitos moradores ocultassem informações sobre os seus doentes. Outro motivo para que isso ocorresse dizia respeito às condições precárias de funcionamento dos hospitais, que motivaram apreensão nos recifenses necessitados dos seus serviços. Sobre essa questão, o periódico Liberal Pernambucano denunciou:

\begin{abstract}
Esses hospitais são verdadeiros covis de traficância, onde reinam o desleixo, a negligência e a desordem; são dirigidos por gente reconhecidamente inepta. Quem para lá entra, por via de regra, não sai com vida e a população pobre tem mais medo do hospital do que o demônio da cruz. Os hospitais são considerados antes como depósitos para se dar passaporte para o cemitério do que como casas destinadas ao curativo e ao alívio dos sofrimentos das vítimas. É tal a crença da população de que a entrada no hospital é morte certa, que os padiolas andam por aí em busca de enfermos, os subdelegados e os inspetores de quarteirão procuram violentar os infelizes para os conduzir aos hospitais e estes reagem com quantas forças tem, com tanto que se vejam livres de semelhante perigo. ${ }^{20}$
\end{abstract}

Em função da resistência que a população recifense demonstrou quanto à possibilidade de hospitalização, a Comissão pôs em prática uma campanha de isolamento dos doentes em suas próprias casas e de desinfecção das mesmas. Para deter a propagação da doença, ao chegarem a uma casa infectada, os membros da companhia retiravam do seu interior os objetos utilizados pelo colérico e imediatamente os incineravam. Em seguida, aplicavam ácido sulfuroso em todos os cômodos desocupados, especialmente nos quartos das vítimas, e lavavam as dependências com água misturada a cloreto de cal. O procedimento se estendia 
por dois dias. ${ }^{21}$ Os agentes de saúde contavam com o apoio da polícia para fazer cumprir as mediadas sanitárias e quarentenas impostas, e garantir o sequestro das casas indicadas pela Comissão. $^{22}$

O órgão de saúde ficou responsável pela organização e fiscalização do desempenho dos serviços de desinfecção e tinha poderes para sequestrar as casas dos doentes de cólera identificadas na cidade. Os coléricos encontrados nessas residências eram, de pronto e sem direito de recusa, encaminhados para os hospitais. ${ }^{23}$ Contudo, os focos de contágio, sobretudo dos mocambos, estavam espalhados por todo o Recife, inclusive pelos bairros mais urbanizados. Isso levou as autoridades a se preocuparem também com a elaboração de um plano de higienização da cidade; visando limpar as ruas, praias, praças, mercados, o cais e todos os locais públicos onde houvesse entulhos e alagados. Foi estabelecida uma intensa fiscalização sobre os gêneros alimentícios, com ordem expressa para que fossem destruídos aqueles que estivessem deteriorados. As fontes de água potável também foram rigorosamente policiadas, sendo interditadas à lavagem de roupas e animais. ${ }^{24}$

A população foi instruída, por meio de posturas municipais divulgadas no Diário de Pernambuco, a manter a higiene das suas residências. Segundo essas posturas:

Todos os proprietários de casas habitadas são obrigados a tê-las exteriormente limpas, caiando ou pintando-as, logo que se acharem denegridas ou sujas, e a reparar todo e qualquer estrago em suas paredes. Todos os moradores da cidade serão obrigados a conservarem limpas, sem lamas e imundícies os quintais das suas residências, dando fácil esgoto às águas pluviais. ${ }^{25}$

Para reduzir o risco de contágio, os enterramentos deveriam ser realizados imediatamente após a morte. Não raro, os jornais denunciavam que os carros de aluguel que conduziam cadáveres eram utilizados, pouco tempo depois, para a condução dos vivos, isso sem que fosse realizada uma higienização. Também havia o costume de alugar caixões para o transporte dos mortos até as igrejas, que podia favorecer a contaminação daqueles que acompanhavam um cortejo fúnebre em que o caixão fosse utilizado anteriormente por uma vítima de doença contagiosa. Em função desses hábitos, a Comissão de Higiene recomendou que os cadáveres fossem colocados em caixões de madeira totalmente fechados e levados para o cemitério fora da cidade, visto que os sepultamentos em igrejas estavam proibidos, e que todo o material utilizado no serviço fúnebre passasse por uma cuidadosa desinfecção. ${ }^{26}$

A Comissão de Higiene, em relatório apresentado ao presidente da Província no final da epidemia, sobre os procedimentos adotados com relação ao sepultamento dos coléricos, afirmou que no Recife, enquanto reinou a epidemia: 


\begin{abstract}
Nenhum cadáver esteve insepulto e se contratava a condução dos mesmos para o cemitério a carro em qualquer hora do dia ou da noite fechados em caixão e cujo administrador, a quem se recomendava toda a presteza nos enterramentos, tomava $\mathrm{o}$ partido não só de ter cem covas abertas, além dos que eram orçados para cada dia, como de ordenar aos cavadores que uns enterrassem em um dia, enquanto que outros abrissem as covas. Nenhum caso se deu de cólera nesses trabalhadores. ${ }^{27}$
\end{abstract}

Entretanto, uma leitura mais atenta dos jornais da época revela que nem sempre tudo ocorreu satisfatoriamente. Não são poucos os anúncios publicados em que a população denunciava a negligência na condução dos mortos até o cemitério.

\footnotetext{
Numa dessas noites passadas, um cocheiro fúnebre que os cavalos estavam cansados pegou o cadáver que conduzia e atirou sobre a calçada do aterro até que os cavalos tomassem um arzinho. Algumas pessoas moradoras do aterro observaram, apesar de ser mais de meia noite, esse atentado. A peste mata-nos, a fome nos mostra suas garras e os malditos zombam da morte, riem-se da fome e profanam com escárnio os mortos! $!^{28}$
}

É possível que esse tipo de procedimento tenha se tornado comum nos dias mais críticos, tanto pela grande quantidade de mortos que se deveria dar sepultura como pelo pequeno número de fiscais disponíveis para observar os procedimentos adotados pelos cocheiros dos carros fúnebres.

As estratégias utilizadas pelos médicos recifenses para combater a epidemia indicavam um momento de transição de uma medicina das doenças para uma medicina da saúde. Eles deixavam de localizar a origem das doenças no corpo do doente e passavam a relacionar o meio-ambiente à ocorrência das enfermidades. Dessa forma, a insalubridade do ambiente urbano passou a ser identificado como fator desencadeante das epidemias que assolavam a cidade, o que fez surgir a necessidade de eliminar as condições que favoreciam o seu aparecimento. Para esses médicos, a cidade era causa das doenças, principalmente pela desordem física e social que lhe era própria e que deveria ser objeto de fiscalização e de rígido controle pelas autoridades sanitárias (Machado, 1978, p.248-249).

Essa forma de interpretar e de agir sobre o espaço urbano foi utilizada ao longo dos séculos XIX e XX, quando a organização das cidades brasileiras passou a ser objeto de grandes intervenções que tinham como referencial os discursos de médicos e engenheiros. Os objetivos eram ordenar e higienizar o espaço habitado, proporcionar melhores condições de salubridade às classes populares que viviam em condições precárias e evitar a propagação das epidemias. Um uso exemplar dessa forma de intervenção ocorreu durante a epidemia de febre amarela que atingiu Campinas (SP) em 1889, abalando a economia e a demografia da cidade. 
Muitas medidas implementadas pelo poder municipal para melhorar a salubridade urbana de antigos e novos edifícios, bem como a vigilância, interdição e demolição de muitas casas e cortiços, tornaram-se impopulares. Naquele contexto, a Comissão Sanitária agiu com plenos poderes conferidos pelo Estado para coordenar os trabalhos de saneamento e de combate à febre amarela, tornando-se, de certo modo, "senhora da cidade", com ações que afetaram diretamente a vida dos habitantes (Martins, 2015, p.507-524).

\section{Aos pobres, caridade e controle social}

Durante a epidemia de cólera no Recife, os higienistas conquistaram aliados importantes em sua estratégia de realizar melhorias nas condições de salubridade pública da cidade. Além das autoridades municipais e provinciais, o combate à epidemia também mobilizou outros setores da sociedade, como as Comissões de Beneficência fundadas pelas camadas mais abastadas da população. Elas gerenciavam a distribuição de roupas, alimentos e remédios nas casas dos doentes que não fossem encaminhados aos hospitais. Também encaminhavam mendigos aos asilos de mendicidade para que se banhassem e vestissem roupas limpas, ajudavam doentes em suas casas e levavam pessoas necessitadas para os hospitais. Essas comissões também foram incumbidas de auxiliar na manutenção do controle social; fiscalizando o cumprimento das leis, transmitindo as ordens médicas e observando os cuidados relativos à higiene. $^{29}$

A vigilância médica foi outra forma de assistência utilizada durante a epidemia de cólera no Recife. Ela era realizada através da presença dos médicos nos domicílios pobres, geralmente localizados nos extremos da cidade. Nessas casas, eles observavam atentamente as condições de vida dos habitantes e quais enfermidades eram mais frequentes, a qualidade da água que era consumida, a circulação de ar dentro dos aposentos e o tipo de trabalho dos moradores. A partir desses relatos era possível se ter um levantamento das condições sociais das camadas pobres da população. ${ }^{30}$

Essa maior preocupação em assistir aos necessitados sugere uma tentativa das autoridades e das classes mais abastadas de exercerem um maior controle sobre as camadas mais pobres da população. Isso porque acreditavam que elas ofereciam risco, tanto para manutenção da ordem pública quanto de contágio propriamente dito. Mas, ao que parece, esse controle não foi mantido por muito tempo. No momento mais trágico da epidemia, as comissões foram acusadas de não estarem cumprindo o papel de auxilio aos necessitados que lhes era reservado: 
Cresce cada dia mais em uma proporção espantosa o número de falecidos da epidemia nesta cidade. O desânimo é geral e geral também é o abandono dos doentes nas casas que morrem sem ter quem lhes apliquem medicamentos e outros socorros. Não sabemos o que têm feito as chamadas Comissões de Beneficência que se formaram nas diferentes freguesias para socorrer a pobreza. Temos visto falecer muitas pessoas na miséria, sem ter ao menos um lençol para cobrirem-se, sem que um só membro dessas comissões se apresente para socorrer esses infelizes. ${ }^{31}$

Estudando as questões acerca do que denominou "ideologia da higiene", Sidney Chalhoub afirma que, no Rio de Janeiro do século XIX, as classes pobres não passaram a ser vistas como classes perigosas apenas porque poderiam oferecer problemas para a organização do trabalho e a manutenção da ordem pública. Eles passaram a representar risco de contágio no sentido literal, sobretudo quando foi diagnosticado que os hábitos de moradia dos pobres eram nocivos à sociedade, e isto porque as habitações coletivas (os cortiços) eram consideradas focos de irradiação de epidemias (Chalhoub, 1996, p.92).

$\mathrm{O}$ argumento pode nortear a análise das atitudes das autoridades com relação aos setores menos favorecidos da população do Recife durante a epidemia de cólera de 1856. Tomando-se por "menos favorecidos" os escravos, os libertos e os livres pobres, a preocupação com a ordem pública no Recife encontra explicação na medida em que se percebe que, nos tempos do cólera, boa parte da população da se encaixava neste perfil. Eles circulavam pelas ruas do Recife realizando trabalhos para os seus contratantes ou senhores. A convivência desses indivíduos em meio ao resto da população era tolerada e, de certa forma, necessária em função das características da cidade, sobretudo na primeira metade do século XIX. Desprovida de serviços básicos, ela utilizava a força de trabalho dos pobres para viabilizar o seu funcionamento. Havia também os escravos que, fugidos das fazendas, procuravam abrigo nas ruas sinuosas e becos escuros da cidade e outros que nela "viviam por si”, pagando jornal aos seus proprietários com os ganhos dos trabalhos realizados e morando em lugares insalubres. ${ }^{32}$ Era essa população "menos favorecida", considerada perigosa, que o poder público tentava controlar através das políticas de auxílio aos necessitados.

Figuras que faziam parte da paisagem do Recife no século XIX, os mendigos e as prostitutas foram, provavelmente, os que tiveram seu cotidiano mais severamente controlado em função da epidemia. A preocupação das autoridades com o perigo supostamente representado por essas pessoas tornou-se visível em um relatório, apresentado pela Comissão de Higiene Pública ao presidente da província, contendo sugestões sobre medidas a serem implantadas com o objetivo de preservar o Recife da invasão do cólera. Nele, os membros da Comissão deixavam clara a intenção de excluir estes elementos do convívio social da cidade. 
A construção de lugares específicos para abrigar e empregar os mendigos aparecia como solução para retirar das ruas estes indivíduos considerados especuladores da boa fé dos transeuntes e prováveis focos de contaminação para o resto da população.

Cada vez mais se reconhece a necessidade de depósitos de mendicidade. Os recursos que ela encontra nesta cidade, onde se confunde com a pobreza, não temendo afirmar que muitos poderiam deixar de andar às esmolas, no que se empregam por especulação. A qualquer hora do dia, ainda se encontram indivíduos chagados que, sentados nas pontes que reúnem os três bairros de que se compõem a cidade, aturdem os ouvidos dos viajantes com monótonas e estudadas lamentações. Ainda as portas das igrejas servem de asilo noturno para muitos. Se a mendicidade afligisse só pelo seu aspecto, não passaria isto de um desgosto, mas ela é um dos focos da imoralidade. Recolhidos a depósitos todos os mendigos que se encontrassem e sujeitos a trabalhos que comportassem as suas forças, muitos desistiriam da especulação e, no fim de poucos anos, só restaria a verdadeira pobreza que, de ordinário, não é composta desses. ${ }^{33}$

As prostitutas não receberam um tratamento mais gentil do que aquele reservado aos mendigos, pois eram consideradas ameaças, não apenas à saúde, mas também à moral e aos bons costumes da população.

Tratou a Comissão de Higiene Pública da prostituição apontando os males que dela resultavam à população, pediu que adotassem medidas que a refreassem, sujeitando à visita médica e aos regulamentos policiais aquelas mulheres que a ela se dessem. A Comissão reconhece a dificuldade que se terá de submeter às prostitutas a medidas sanitárias e policiais visto que, de pronto, se não destroem preconceitos populares e hábitos inveterados; mas é preciso que se dê princípio ao refreamento da prostituição, não devendo parecer estranho o que propõe a Comissão, porquanto todos os países civilizados têm adotado regulamentos severos para este fim. Se não é possível conseguir-se suprimi-la da sociedade, reprimir-se-ão os seus excessos, e isto é digno da atenção do Governo, porquanto a prostituição não só influi sobre a saúde da população, se não sobre a sua moralidade. ${ }^{34}$

Em tempos de epidemia uma maior atenção sobre essas vertentes da população - os mendigos e as prostitutas - revelava, principalmente, a intenção de eliminar os focos de contágio que pudessem representar. Da mesma forma, a assistência aos necessitados poderia estar relacionada à tentativa das autoridades e dos higienistas de manter um maior controle da população mais pobre e, na medida em que monitorava a salubridade das suas habitações, também teria por fim a proteção da saúde dos demais recifenses. Esses eram traços da medicina social preconizada no Recife em tempos de epidemia, um saber médico que não se preocupava apenas com o indivíduo doente, mas também com a proteção dos sãos.

A partir do episódio relatado, pode-se concluir que as estratégias de combate ao cólera em Recife significaram a intensificação do controle do poder público provincial sobre a população e a cidade, um controle ancorado no discurso dos higienistas que pregavam a 

da população.

\section{Notas:}

${ }^{1}$ A instalação da Escola de Anatomia, Cirurgia e Medicina; e do Hospital Militar do Rio de Janeiro foi uma sugestão do pernambucano José Correia Picanço, então Cirurgião-Mor do Reino. MIRANDA, Carlos Alberto Cunha. Os curandeiros e a ofensiva médica em Pernambuco na primeira metade do século XIX. CLIO. Revista de Pesquisa Histórica do Programa de Pós-Graduação em História, n.19, p.95-110. UFPE. Recife: Editora Universitária, 2001, p.101.

${ }^{2}$ Os médicos Joaquim Aquino Fonseca, José Joaquim de Moraes Sarmento, Simplício Antônio Peregrini Maciel Monteiro e Sinfrônio Olímpio César Coutinho integravam esse grupo. Idem, p.110.

${ }^{3}$ O Conselho Geral de Salubridade iniciou suas atividades em 1845, atuando até 1855 , quando foi substituído pela Comissão de Higiene Pública, também sob a direção do dr, Aquino e, depois, do Dr. Cosme de Sá Pereira. Em 1872, a Comissão foi sucedida pela Inspetoria de Higiene Pública, que permaneceu sob a direção do Dr Lobo Moscoso até 1886. FREITAS, Octávio de. Um século de medicina e hygiene no Nordeste. In: FREYRE, Gilberto (Org.) Livro do Nordeste. Recife: Arquivo Público Estadual de Pernambuco, 1979, p.121.

${ }^{4}$ O Cemitério Senhor Bom Jesus da Redenção, conhecido como Cemitério de Santo Amaro, foi projetado pelo engenheiro José Mamede Alves Ferreira e inaugurado em 1을 de março de 1851, com o objetivo inicial de receber os corpos das vítimas da febre amarela, que não poderiam ser sepultadas em igrejas, como era costume na época. Para maiores informações sobre o tema, ver SIAL, Vanessa Viviane de Castro. Das igrejas ao cemitério: políticas públicas sobre a morte no Recife do século XIX. Dissertação (Mestrado em História). UNICAMP. Campinas/ SP, 2005.

${ }^{5}$ Relatório do estado sanitário da província de Pernambuco durante o ano de 1856. Recife: Tipografia M. F. de Faria, 1857, p.5.

${ }^{6}$ Diário de Pernambuco, 3 dez de 1855, p.3.

${ }^{7}$ Coleção de Trabalhos do Conselho Geral de Salubridade Pública. Recife: Typografhia S. Caminha, 1845, p.40.

${ }^{8}$ Coleção de Trabalhos do Conselho Geral de Salubridade Pública. Recife: Tipografia S. Caminha, 1845, p.42.

${ }^{9}$ Em 1885, o Dr. Cosme de Sá Pereira trataria largamente sobre o assunto em sua obra "Reminiscência do Cólera em Pernambuco".

${ }^{10}$ Ofícios da Presidência da Província à Câmara Municipal do Recife, 02 de junho de 1855 . Instituto Arqueológico, Histórico e Geográfico Pernambucano.

${ }^{11}$ Provedoria de Saúde do Porto, 15 de junho de 1855. Arquivo Público Estadual Jordão Emereciano.

${ }^{12}$ Vigilância Sanitária, 21 de junho de 1855. Arquivo Público Estadual Jordão Emereciano.

${ }^{13}$ Vigilância Sanitária, 26 de junho de 1855. Arquivo Público Estadual Jordão Emereciano.

${ }^{14}$ Salubridade Pública, 24 de novembro de 1855. Arquivo Público Estadual Jordão Emereciano.

${ }^{15}$ Coleção dos trabalhos do Conselho Geral de Salubridade Pública da Província de Pernambuco (1845-1851). Recife: Tipografia S. Caminha, 1851, p.37.

${ }^{16}$ Salubridade Pública - Ofício da Comissão de Higiene Pública ao Presidente da Província de Pernambuco. 28 de fevereiro de 1855. Arquivo Público Estadual Jordão Emereciano.

${ }^{17}$ Idem.

${ }^{18}$ Relatório do estado sanitário da província de Pernambuco no ano de 1856. Comissão de Higiene Pública de Pernambuco. Recife: Tipografia. Manoel F. de Faria, 1857, p.6.

${ }^{19}$ Idem.

${ }^{20}$ Liberal Pernambucano, 27 de fevereiro de 1856, p.4.

${ }^{21}$ Salubridade Pública - Ofício da Comissão de Higiene Pública ao Presidente da Província de Pernambuco. 12 de janeiro de 1856. Arquivo Público Estadual Jordão Emereciano.

${ }^{22}$ Relatório do estado sanitário da província de Pernambuco no ano de 1856. Comissão de Higiene Pública de Pernambuco. Recife: Tipografia Manoel F. de Faria, 1857, p.23.

${ }^{23}$ Diário de Pernambuco, 28 de abril de 1856, p.6. "Discurso do dr Cosme de Sá Pereira quando do seu afastamento da Comissão de Higiene Pública".

${ }^{24}$ Relatório do estado sanitário da província de Pernambuco no ano de 1856. Comissão de Higiene Pública de Pernambuco. Recife: Tipografia. Manoel F. de Faria, 1857, p.28.

${ }^{25}$ Diário e Pernambuco, 05 de janeiro de 1856, p.2. 


\footnotetext{
${ }^{26}$ Salubridade Pública - Ofício de Comissão de Higiene Pública ao presidente da Província de Pernambuco. 12 de janeiro de 1856. Arquivo Público Estadual Jordão Emereciano.

${ }^{27}$ Relatório do estado sanitário da província de Pernambuco durante o ano de 1856. Comissão de Higiene Pública de Pernambuco. Recife: Tipografia Manoel F. de Faria, 1857, p.20.

${ }^{28}$ Diário de Pernambuco, Recife 03 de março de 1856, p.4.

${ }^{29}$ Diário de Pernambuco, 26 de janeiro de 1856, p.6.

${ }^{30}$ Relatório do estado sanitário da província de Pernambuco no ano de 1856. Comissão de Higiene Pública de Pernambuco. Recife: Tipografia. Manoel F. de Faria, 1857.

${ }^{31}$ Liberal Pernambucano, 22 de fevereiro de 1856, p.8.

${ }^{32} \mathrm{Na}$ obra "Liberdade: rotinas e rupturas do escravismo no Recife, 1822-1850", Marcus Carvalho discute a escravidão urbana no Recife na primeira metade do século XIX. É um momento imediatamente anterior à epidemia de cólera de 1856, em que a participação dos cativos nos diversos movimentos revolucionários e mesmo as suas lutas particulares em busca das liberdades deu origem a uma atmosfera de perigo relacionado ao ambiente urbano, uma situação que poderia se agravar ainda mais no momento crítico de uma epidemia e que requeria das autoridades a formulação de estratégias de controle social.

${ }^{33}$ Relatório do Estado Sanitário da Província de Pernambuco. Comissão de Higiene Pública. Recife: Tipografia Manoel F. de Faria Recife, 1855, p.32.

${ }^{34}$ Idem, p. 35 .
}

\section{Referências Bibliográficas}

ARRAIS, Raimundo. O pântano e o riacho: a formação do espaço público no Recife do século XIX. São Paulo: Humanitas/ USP, 2004.

ANDRADE, Gilberto Osório de. A Cólera-Morbo. Um momento crítico na história da medicina em Pernambuco. $2^{a}$ ed. Recife: FUNDAJ - Massangana, 1989.

CARVALHO, Marcus. J. M. de. Liberdade: rotinas e rupturas do escravismo no Recife (1822-1850). Recife: Ed. Universitária da UFPE. 2002.

CHERNOVIZ, Pedro Napoleão. Dicionário de Medicina Popular. $6^{\mathrm{a}}$ ed. Paris: A. Roger \& F. Chernoviz, 1890, v.2.

COSTA, Francisco Pereira da Costa. Anais Pernambucanos. Recife: FUNDARPE, 1984, v.4. DINIZ, Ariosvaldo da Silva. Cólera: Representações de uma angústia coletiva. A doença e o imaginário social no século XIX no Brasil. 1997. Doutorado em História - IFCH UNICAMP.Campinas, 1997.

FARIAS, Rosilene Gomes. Pai Manoel, o curandeiro africano, e a medicina no Pernambuco imperial. História, Ciências, Saúde - Manguinhos. Rio de Janeiro, v. 19, supl. 1, dez. 2012.

FOUCAULT, Michel. A política da saúde no século XVIII. In FOUCAULT, Michel. Microfísica do Poder. Rio de Janeiro: Edições Graal, 1979.

FREYRE, Gilberto (Org.) Livro do Nordeste. Recife: Arquivo Público Estadual de Pernambuco, 1979.

GALVÃO, Sebastião. Diccionário Chorográfico, Histórico e Estatístico de Pernambuco. (Q e R) $2^{\text {a }}$ ed. Imprensa Nacional: Rio de Janeiro, 1921.

MACHADO, Roberto. Dan (a)ção da Norma: a medicina social e a constituição da psiquiatria no Brasil. Rio de Janeiro: Graal, 1978.

MARTINS, Valter. Cidade-laboratório: Campinas e a febre amarela na aurora republicana. História, Ciências, Saúde - Manguinhos, Rio de Janeiro, v.22, n.2, abr.-jun. 2015, p.507-524.

MIRANDA, Carlos Alberto Cunha. Os curandeiros e a ofensiva médica em Pernambuco na primeira metade do século XIX. CLIO. Revista de Pesquisa Histórica do Programa de PósGraduação em História, n 19. UFPE. Recife: Editora Universitária, 2001. 
NASCIMENTO, Dilene Raimundo do; SILVA, Matheus Alves Duarte da. "Não é meu intuito estabelecer polêmica": a chegada da peste ao Brasil, análise de uma controvérsia, 1899. História, Ciências, Saúde - Manguinhos, Rio de Janeiro, v.20, supl., nov. 2013, p.1271- 285. OUTTES, Joel. O Recife: gênese do urbanismo 1927-1943. Recife: Massangana, 1997.

PIMENTA, Tânia Salgado. Terapeutas populares e instituições médicas na primeira metade do século XIX. In. Artes e Ofícios de Curar no Brasil: capítulos de história social. Sidney Chalhoub (org.) - Campinas, SP: UNICAMP, 2003.

PIMENTA, Tânia Salgado. Terapeutas populares e instituições médicas na primeira metade do século XIX. In. Artes e Ofícios de Curar no Brasil: capítulos de história social. Sidney Chalhoub (org.) - Campinas, SP: UNICAMP, 2003.

SAMPAIO, Gabriela dos Reis. Nas trincheiras da cura: as diferentes medicinas no Rio de Janeiro imperial. Campinas, SP: UNICAMP, 2001.

SETTE, Mário. Arruar. História pitoresca do Recife Antigo. Rio de Janeiro: Livraria da Casa do Estudante do Brasil, 1948.

SIAL, Vanessa Viviane de Castro. Das igrejas ao cemitério: políticas públicas sobre a morte no Recife do século XIX. Dissertação (Mestrado em História). UNICAMP. Campinas/ SP, 2005.

SOUZA, Christiane Maria Cruz de. A gripe espanhola na Bahia: saúde, política e medicina em tempos de epidemia. Salvador: EdUFBA; Rio de Janeiro:Editora Fiocruz, 2009. 